\title{
Inferring microevolution from museum collections and resampling: lessons learned from Cepaea
}

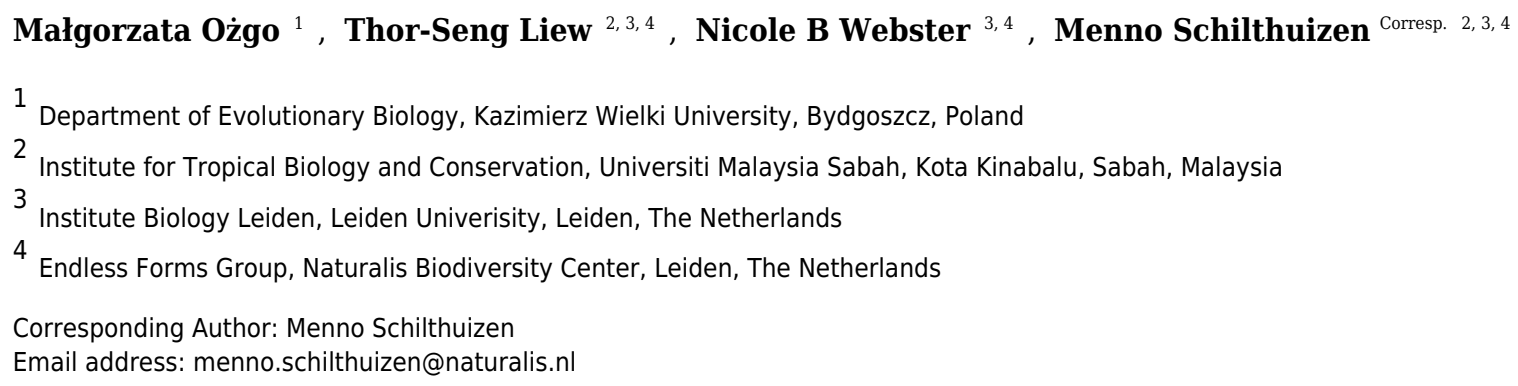

Natural history collections are an important and largely untapped source of long-term data on evolutionary changes in wild populations. Here, we utilize three large geo-referenced sets of samples of the common European land-snail Cepaea nemoralis stored in the collection of Naturalis Biodiversity Center in Leiden, the Netherlands. Resampling of these populations allowed us to gain insight into changes occurring over 95, 69, and 50 years. Cepaea nemoralis is polymorphic for the colour and banding of the shell; the mode of inheritance of these patterns is known, and the polymorphism is under both thermal and predatory selection. At two sites the general direction of changes was towards lighter shells (yellow and less heavily banded) which is consistent with predictions based on ongoing climatic change. At one site no directional changes were detected. At all sites there were significant shifts in morph frequencies between years, and our study contributes to the recognition that short-term changes in the states of populations often exceed longterm trends. Our interpretation was limited by the few time points available in the studied collections. We therefore stress the need for natural history collections to routinely collect large samples of common species, to allow much more reliable hind-casting of evolutionary responses to environmental change. 
1 Inferring microevolution from museum collections and resampling: lessons learned

2 from Cepaea

4 Malgorzata Ożgo ${ }^{1}$, Thor-Seng Liew ${ }^{2,3,4}$, Nicole B Webster ${ }^{3,4}$, Menno Schilthuizen ${ }^{2,3,4}$ 5

61 Department of Evolutionary Biology, Kazimierz Wielki University, Bydgoszcz, Poland

72 Institute for Tropical Biology and Conservation, Universiti Malaysia Sabah, Kota Kinabalu, 8 Sabah, Malaysia

93 Institute Biology Leiden, Leiden Univerisity, Leiden, The Netherlands

104 Endless Forms Group, Naturalis Biodiversity Center, Leiden, The Netherlands 11

12 Corresponding Author: Menno Schilthuizen; Email address: menno.schilthuizen@naturalis.nl 13

\section{Abstract}

17 Natural history collections are an important and largely untapped source of long-term data on evolutionary changes in wild populations. Here, we utilize three large geo-referenced sets of samples of the common European land-snail Cepaea nemoralis stored in the collection of Naturalis Biodiversity Center in Leiden, the Netherlands. Resampling of these populations allowed us to gain insight into changes occurring over 95, 69, and 50 years. Cepaea nemoralis is polymorphic for the colour and banding of the shell; the mode of inheritance of these patterns is known, and the polymorphism is under both thermal and predatory selection. At two sites the general direction of changes was towards lighter shells (yellow and less heavily banded) which is consistent with predictions based on on-going climatic change. At one site no directional changes were detected. At all sites there were significant shifts in morph frequencies between years, and our study contributes to the recognition that short-term changes in the states of populations often exceed long-term trends. Our interpretation was_limited by the few time points available in the studied collections. We therefore stress the need for natural history collections to routinely 
30 collect large samples of common species, to allow much more reliable hind-casting of

31 evolutionary responses to environmental change.

32

33

34

35

36

37

38

39

40

41

42

43

44

45

46

47

48

49

50

51

52

53

54

55

56 57 relatively few.

58 Other sources of long-term data include fisheries reports or trophy measurements (e.g., Sharpe \&

59 Hendry, 2009; Shackell et al., 2010; Douhard et al., 2016), and, especially, natural history 60

Evolutionary processes occurring over time-scales as short as decades or years are increasingly documented, especially in the context of human alterations of the environment, including pollution, harvest, or species introductions (Hendry et al., 2017; Schilthuizen, 2018). Such rapid evolutionary changes, taking place generation-by-generation, can have important consequences for populations, ecosystems, and human societies (Palkovacs et al., 2012; Kinnison et al., 2015; Hendry et al., 2017). The interest in the reciprocal influences between ecology and evolution has been growing recently, and while the general picture of eco-evolutionary dynamics is coming into focus, many questions remain open to investigation (Hendry, 2013; Kinnison et al., 2015; Hendry, 2017). One of the factors limiting progress in this field is the scarcity of data, especially long-term records from natural populations (Kingsolver \& Pfennig, 2007; Siepielski et al., 2009, 2013). Surprisingly, such time-series appear to be more readily available for fossils than for contemporary populations (Bell, 2010). Unlike in other studies such as, e.g., spatial analyses, this lack cannot easily be remedied by applying more effort, as available data are limited to the studies previously initiated and maintained. Notable examples include studies on the Darwin's finches in the Galápagos (Grant \& Grant, 2014), the peppered moth Biston betularia in England (Cook \& Saccheri, 2013), the damselfly Ischnura elegans (Le Rouzic et al., 2015) or the polymorphic marine snail Littorina saxatilis in Sweden (Johannesson \& Butlin, 2017). In polymorphic land snails, studies based on annual recording of morph frequencies over extended periods of time were carried out on Cepaea nemoralis in England (Cain et al., 1990; Bell, 2010), and on Theba pisana in Australia (Johnson, 2011). Long-term monitoring of natural populations requires many years of work in often challenging field conditions, and studies of this kind remain collections. Natural history collections are exceptional in that they contain "raw data" - the 
61 actual specimens, and not only records associated with specimens (Schilthuizen et al., 2015), and

62 they often date back 100 years or even more. Their value is increasingly recognized (Holmes et

63 al., 2016; Linck et al., 2016), but they remain a largely untapped resource. Among museum

64 collections, mollusks have a prominent place. Their beauty has always appealed to naturalists

65 and they have been collected extensively. Because mollusk shells are relatively easy to maintain

66 they constitute an important part of museum collections worldwide (Viniarski, 2016; Breure \&

67 Araujo, 2017).

68 In this paper we identified several large geo-referenced samples of the land snail Cepaea

69 nemoralis in the collection of Naturalis Biodiversity Center in Leiden, the Netherlands, and we

70 resampled these populations in the field in 2010. Cepaea nemoralis is a common European land

71 snail species with a broad distribution. It has a distinctive shell polymorphism: its shells can be

72 yellow, pink or brown and bear up to five spiral bands; the mode of inheritance of these

73 characteristics is well established (Murray, 1975). The environmental drivers of selection include

74 climate and visually hunting predators, and morph frequency shifts in response to these pressures

75 have been documented (reviews in, e.g., Cook, 1998, 2017; Ożgo, 2008). The system has been

76 utilized extensively, but many questions remain unanswered; the most important among them

77 concern the temporal and spatial patterns of selection. The aim of the present study is to add to

78 the understanding of evolutionary processes occurring in populations of Cepaea nemoralis over

79 extended periods of time. The use of museum collections allowed us to gain insight into changes

80 occurring over 95,69 , and 50 years.

81

82 Materials and Methods

83

84 Historical Baseline Data

85 We used the dry Mollusca collection of Naturalis Biodiversity Center to locate large samples of

86 Cepaea nemoralis from the Netherlands with locality information precise enough to make re-

87 sampling possible. We identified three such sets of samples (at the time of writing, these samples

88 had not yet received collection numbers; however, they were held in the special "large Cepaea

89 sample" section):

90 (1) Lobith. Shells collected by H. Wolda and students on 20th April $1960(\mathrm{~N}=368), 27-28$ th

91 April $1961(\mathrm{~N}=398)$, and 10-14th April $1962(\mathrm{~N}=1657)$ at 13 positions along a 400-m section 
92 of dike on the river bank along the Rhine $\left(51.859^{\circ} \mathrm{N} 6.085^{\circ} \mathrm{E}\right)$. The samples were used for a

93 study on stability of a steep c. 20-m-wide cline located along the section, where unbanded yellow

94 shells increase in frequency at the expense of banded yellow and unbanded "red" shells (Wolda,

95 1969). Wolda (1969) reports on a total of 26,230 individuals, and writes that most samples

96 consisted of mostly living snails and a small proportion of dead shells. Since Wolda states that

97 all living snails were returned to their collection localities after scoring, we conclude that the

98 Naturalis samples $(\mathrm{N}=2423)$ consist only of snails that were collected as empty shells. Wolda

99 (1969) also reports that the vegetation along the dike grades from a dense river-dune vegetation

100 on sand, rich in nutrition and calcium, to more open river-dune vegetation on coarse, rich, and

101 dry sand with calcium.

102 (2) Empe. Shells collected by J.C. van Heurn in May $1915(\mathrm{~N}=468)$ and July $1951(\mathrm{~N}=340)$ at

103 Empe estate $\left(52.145^{\circ} \mathrm{N} 6.142^{\circ} \mathrm{E}\right)$. The sample of 1915 is labelled as follows: "Collected at

104 random in one site on the main road from Zutphen to Voorst, in the Zutphen municipality,

105 directly opposite the manor "Empe". The collection consists of 451 adults and 17 juveniles. [...]

106 The habitats are the elm stems as well as the roadside-verges. In the verges there were no nettles

107 or generally tall herbs, but there was a row of elm-bushes, mixed with some hawthorn, grasses

108 and other low herbs" (translated from Dutch by M.S.). The sample of 1951 is labelled, "Road

109 south of Voorst. Opposite "Empe"”. We conclude that both samples were taken at the exact same 110 locality.

111 (3) Allemansgeest. Shells collected by W.C. van Heurn in summer $1942(\mathrm{~N}=500)$ and $1943(\mathrm{~N}$

$112=772$ ) on the $150 \times 50 \mathrm{~m}$ peninsula "Allemansgeest" at the confluence of Vliet and Korte Vliet,

113 near Voorschoten $\left(52.143^{\circ} \mathrm{N} 4.468^{\circ} \mathrm{E}\right)$. The location and samples were reported on by Van

114 Heurn $(1943,1945)$. He describes the habitat as "a narrow spit of land, planted with willow, ash,

115 and some alder, among which a wild herb vegetation appears in summer, consisting mostly of

116 nettles" (translated from Dutch by M.S.). He also reports on a set of samples from 1941, which

117 we could not locate. The collected numbers reported for 1942 and 1943 were, respectively, 535

118 and 787, suggesting that a small number of individuals had been lost from the samples. We

119 assume these to have been random subsets.

120 (A fourth set, from the vicinity of Eenrum, was already reported on previously; Ożgo \&

121 Schilthuizen, 2012.)

122 


\section{Resampling in $\mathbf{2 0 1 0}$}

124 We visited these exact locations in 2010. All sites were identifiable and still contained Cepaea

125 nemoralis. At Lobith, the vegetation remained as described by Wolda (1969). Since snail

126 densities were apparently much lower than in Wolda's time, we did not sample Wolda's

127 individual subsections, but instead pooled all material from the entire 400-m length of dike (20-

12822 June 2010). At Empe, no patch of vegetation exactly matched the description by Van Heurn,

129 so we sampled from two different patches facing the façade of the manor house: Empe-1

$130 \quad\left(52.1457^{\circ} \mathrm{N} ; 6.1435^{\circ} \mathrm{E}\right.$; reeds, nettles; 20-22 June 2010$)$ and Empe-2 $\left(52.1456^{\circ} \mathrm{N} ; 6.1426^{\circ} \mathrm{E}\right.$;

131 maple forest; 20-22 June 2010). At Allemansgeest, finally, the vegetation had become more

132 park-like, with lawns, tall poplars, and only a few patches where a herbaceous layer was present.

133 Cepaea densities were low, so we sampled multiple times, on 21 June, 22 August, and 13

134 September 2010. At all sites, we collected juveniles and adults, (fresh) dead and alive. Juveniles

135 too small to judge the colour morph accurately were not included. Fieldwork was conducted

136 under permission FF/75A/2010/021a from the Netherlands Ministry of Agriculture, Nature, and

137 Food Quality.

138

139

\section{Shell Morph Scoring Scheme}

141 Each individual from the museum samples and the recent samples was scored following the same

142 scoring scheme as described in Cain and Sheppard (1954). We investigated three types of

143 changes in shell morph frequencies between the historical baseline data and the resampling data:

144 (1) changes in shell ground colour: yellow (Y), pink (P), and brown (B); (2) changes in banding

145 categories: mid-banded (00300; M), three-banded (00345; T), five-banded (12345; F), and other

146 banding $(\mathrm{O})$; and (3) changes in yellow effectively unbanded (YeU), the aggregate phenotype

147 that includes all yellow shells with two upper bands missing (Y00XXX).

148

\section{Data analysis}

150 At each site, and for each pair of samples, we performed separate chi-square homogeneity tests

151 for each of the three types of morph change (banding, colour, and proportion of YeU) to examine

152 whether there is evidence of a change in frequency between years (Figure 1). Although we

153 recorded the frequency of all morph categories, we excluded categories from the homogeneity 
154 tests when the morph frequency in the baseline year was equal to zero. The significance level of

155 the chi-square test was set at $p=0.05$, and we tested for the following changes in frequency

156 between the baseline and resampling years. Colour: yellow, pink, and brown; shell banding: mid-

157 banded, three-banded and five-banded; YeU: Yellow-effectively unbanded. All the analyses

158 were calculated in Excel (Microsoft) (Supplementary Data 1).

159

160

\section{Results}

162

163 Full results are given in Figure 1 and Supplementary Data 1-4. We found no significant 164 differences in colour $\left(\chi^{2}=2.38\right.$, d.f. $\left.=2, p=0.30\right)$ or banding morph frequencies $\left(\chi^{2}=2.03\right.$, d.f. $165=2, p=0.36$ ) between the two patches sampled at Empe in 2010, so we pooled the data.

166

167

168

169

170

171

172

173

174

175

176

177

178

179

180

181

182

183

184

Altogether, our 2010 sample sizes for Lobith, Empe, and Allemansgeest were $\mathrm{N}=131, \mathrm{~N}=189$, and $\mathrm{N}=77$, respectively (Supplementary data 2-4). Parts of these samples have been stored as vouchers in the alcohol collection of Naturalis Biodiversity Center, under collection numbers RMNH.5004222 (Allemansgeest), RMNH.5004223-5004224 (Lobith) and RMNH.50042255004227 (Empe).

In Lobith, significant changes in the frequencies of colour, banding, and the yellow effectively unbanded (YeU) phenotype occurred over the study period (Figure 1). There was a shift in the frequency of yellow shells from $85 \%$ in 1960 to $79 \%$ in $1961\left(\chi^{2}=4.4, p<0.05\right)$, and then to $84 \%$ in $1962\left(\chi^{2}=4.8, p<0.05\right)$. Roughly the same frequency of yellow $(83 \%)$ was recorded in 2010. The banding pattern was significantly different in 2010 as compared to the years 1960 $1962\left(1960-2010: \chi^{2}=18.5, \mathrm{p}<0.001 ; 1961-2010: \chi^{2}=12.5, \mathrm{p}<0.01 ; 1962-2010: \chi^{2}=28.1, \mathrm{p}<\right.$ 0.001 ), which included a decrease in the frequency of five-banded from $73 \%$ in 1962 to $55 \%$ in 2010 , and an increase in the frequency of usually rare "other banding" snails, in this case the 00045 form, from $6 \%$ in 1962 to $26 \%$ in 2010 . Between 1961 and 1962 the frequency of the $\mathrm{YeU}$ phenotype increased from $48 \%$ to $61 \%\left(\chi^{2}=22.6, p<0.001\right)$. This was due to an increase in the frequency of yellow shells and a simultaneous increase in the frequency of yellow unbanded among yellow shells form $52 \%$ to $64 \%$. Although there were some reversals, together these changes were in the direction of higher frequencies of less heavily banded forms. 
186 In Empe, the population remained relatively stable between samples, with no significant 187 differences in banding patterns or the frequency of YeU. Interestingly, data from 1951 suggest 188 that some shifts in morph frequencies were occurring over that time despite the fact that the 1915 189 and 2010 samples do not differ significantly: the frequency of yellow in 1951 was lower (66\%) 190 and differed significantly from both $1915(75 \%)$ and $2010(77 \%)\left(\chi^{2}=7.1, \mathrm{p}<0.01\right.$ and $\chi^{2}=6.4$, $\mathrm{p}<0.05$, respectively). This corresponded with an increase in the frequency of pink shells in 1921951 from $22 \%$ to $34 \%$.

193

194

In Allemansgeest, a significant change in the frequency of banding morphs occurred between 195 1942 and $1943\left(\chi^{2}=66.4, p<0.001\right)$, including an increase in the mid-banded from $28 \%$ to $48 \%$, and a decrease in five-banded from $51 \%$ to $24 \%$. The frequency of YeU also changed over this time period from $29 \%$ in 1942 to $39 \%$ in $1943\left(\chi^{2}=12.5, \mathrm{p}<0.001\right)$. Colour morphs did not change significantly between those years; the frequency of yellow did increase from $52 \%$ to $62 \%$ between 1943 and 2010 ( $\chi^{2}=2.8$, n.s.). As in Lobith, the overall change was in the direction of lighter shells.

201

202

203

\section{Discussion}

205 The use of natural history museum collections allowed us to analyse evolutionary changes in 206 populations of Cepaea nemoralis that occurred over several decades at three sites in the Netherlands. Our study contributes to the increasing recognition that large changes in the states of populations can occur over very short time scales and exceed in magnitude the long-term trends (Hendry \& Kinnison, 1999; Siepielski et al., 2009). They may result from natural selection

210 in response to biotic or abiotic factors (e.g. changing weather conditions and/or fluctuating 211 selection by predators), from migration, and from random events. The data available in this study 212 do not allow us to draw conclusions about the relative importance of those factors. Historical 213 data from consecutive years show that the changes in the genetic structure of populations were 214 rapid, but as the years of sampling were different in the three sets of data, it remains unknown 215 whether the recorded changes were consistent over different sites. In the long time-scale, the data 
216 from Lobith and Allemansgeest suggest that the general direction of changes was towards higher 217 frequencies of lighter morphs (yellow and less heavily banded), which is consistent with the 218 direction of selection predicted on the basis of the on-going climate change, and this has been 219 shown in some other studies on Cepaea snails (Ożgo \& Schilthuizen, 2012; Cameron et al., 220 2013; Silvertown et al., 2011). The value of the present study lies in the insight we were able to 221 gain into changes in the genetic composition of populations over long time intervals. However, 222 our interpretation is limited by the number of time points that the collections we studied could 223 provide.

224 Thus, an additional reflection from our study concerns the value of long time-series of 225 population samples (lots) maintained in museum collections. The importance of natural history 226 museum collections is increasingly recognized (Schilthuizen et al., 2015, Turney et al., 2015;

227 Holmes et al., 2016) but it is realistic to assume that for reasons of space, resources, and staff, 228 their scope will remain limited, and careful choices of the focus of the on-going and future 229 collection efforts need to be taken. We advocate especially for the collection of time-series of the 230 (often-ignored) common species, with the view of securing future access to the records of 231 population states of currently widespread species. Such collections have the potential of being 232 analysed with the tools and resolution not yet available today, and being used to answer 233 questions which at present are not even anticipated. Current examples of such applications 234 include the vast field of museum genomics (Yeates et al., 2016), studies of amphibian 235 chytridiomycosis (James et al., 2015), or of retroviral integration sites (Cui et al., 2016).

236 Focusing on common species has the advantage of allowing to collect relatively large samples 237 from designated populations at regular intervals. An important reason to focus on common 238 species is that the present biodiversity crisis concerns many species that until recently were 239 common and widespread, but are now in decline (Gaston \& Fuller, 2007; Inger et al., 2015, 240 Petrovan \& Schmidt, 2016). Time-series collections can help document demographic, genetic, 241 and evolutionary processes in populations undergoing distribution shifts, declines, and possibly 242 rebounds. It is the common species with relatively high population numbers that are most likely 243 to undergo evolutionary rescue (Carlson et al., 2014), and time-series collections have the 244 potential of capturing its occurrence in wild populations. 


\section{Acknowledgements}

248 We thank Jeroen Goud and Bram van der Bijl, collection managers of the Naturalis Mollusca

249 collection for providing access to the historical specimens and for arranging the administration of

250 the 2010 vouchers. Henrik Wolda, Rinny Kooi, Wilke van Delden, and Lucy Oosterhoff helped

251 in obtaining additional information on historical collection localities. Laurence Cook, Kerstin

252 Johannesson, and Andrew Hendry reviewed an earlier version of this paper, and their comments

253 helped us to rewrite and improve it.

254

255

256

257

\section{References}

258

Bell G. 2010. Fluctuating selection: the perpetual renewal of adaptation in variable

259

260

environments. Philosophical Transactions of the Royal Society B 365: 87-97.

261

Breure ASH, Araujo R. 2017. The Neotropical land snails (Mollusca, Gastropoda) collected by the 'Comision Cientifica del Pacifico'. PeerJ 5:e3065; DOI 10.7717/peerj.3065

262

263

Cain AJ, Sheppard PM. 1954. Natural selection in Cepaea. Genetics 39: 89-116.

264

265 Cain AJ, Cook LM, Currey JD. 1990. Population size and morph frequency in a long-term study 266 of Cepaea nemoralis. Proceedings of the Royal Society of London B 240: 231-250.

267

268 Cameron RAD, Cook LM, Greenwood JJD. 2013. Change and stability in a steep morph269 frequency cline in the snail Cepaea nemoralis (L.) over 43 years. Biological Journal of the 270 Linnean Society 108: 473-483.

271

272 Carlson SM, Cunningham CJ, Westley PAH. 2014. Evolutionary rescue in a changing world.

273 Trends in Ecology and Evolution 29: 521-530.

274

275 Cook LM. 1998. A two-stage model for Cepaea polymorphism. Philosophical Transactions of 276 the Royal Society of London B 353: 1577-1593. doi:10.1098/rstb.1998.0311 
278 Cook LM. 2017. Reflections on molluscan shell polymorphism. Biological Journal of Linnean

279 Society, in print.

280

281 Cook LM, Saccheri IJ. 2013. The peppered moth and industrial melanism: evolution of a natural 282 selection case study. Heredity 110:207-212.

283

284 Cui P, Löber U, Alquezar-Planas DE, Ishida Y, Courtiol A, Timms P, Johnson RN, Lenz D, 285 Helgen KM, Roca AL, Hartman S, Greenwood AD. 2016. Comprehensive profiling of retroviral 286 integration sites using target enrichment methods from historical koala samples without an 287 assembled reference genome. PeerJ 4:e1847; DOI 10.7717/peerj.1847

288

289

Douhard M, Festa-Bianchet M, Pelletier F, Gaillard J-M, Bonenfant C. 2016. Changes in horn 290 size of Stone's sheep over four decades correlate with trophy hunting pressure. Ecological 291 Applications 26:309-321.

292

293 Gaston KJ, Fuller RA. 2007. Commonness, population depletion and conservation biology.

294 Trends in Ecology and Evolution 23:14-19.

295

296 Grant PR, Grant BR. 2014. 40 Years of evolution. Darwin's finches on Daphne Major Island. 297 Princeton, NJ: Princeton University Press.

298

299

300

Hendry AP. 2013. Key questions in the genetics and genomics of eco-evolutionary dynamics.

301

302 Heredity 111: 456-466.

303

304

Hendry AP. 2017. Eco-Evolutionary Dynamics. Princeton University Press, Princeton.

305

306

307 308
Hendry AP, Kinnison MT. 1999. The pace of modern life: measuring rates of contemporary microevolution. Evolution 53: 1637-1653.

Hendry AP, Gotanda KM, Svensson EI. 2017. Human influences on evolution, and the ecological and societal consequences. Philosophical Transactions B 372: 20160028. 
309 Holmes MW, Hammond TT, Wogan GOU, Walsh RE, Labarbera K, Wommack EA, Martins 310 FM, Crawford JC, Mack KL, Bloch LM, Nachman MW. 2016. Natural history collections as 311 windows on evolutionary processes. Molecular Ecology 25:846-881.

312

313 Inger R, Gregory R, Duffy JP, Stott I, Voříšek P, Gaston KJ. 2015. Common European birds are 314 declining rapidly while less abundant species' numbers are rising. Ecology Letters 18:28-36.

315

316 James TY, Toledo LF, Rödder D, da Silva Leite D., Belasen AM, Betancourt-Román CM, 317 Jenkinson TS, Soto-Azat C, Lambertini C, Longo AV, Ruggeri J, Collins JP, Burrowes PA, Lips 318 KR, Zamudio KR, Longcore JE. 2015. Disentangling host, pathogen, and environmental 319 determinants of a recently emerged wildlife disease: lessons from the first 15 years of amphibian 320 chytridiomycosis research. Ecology and Evolution 5:4079-4097.

321

322 Johannesson K, Butlin RK. 2017. What explains rare and conspicuous colours in a snail? A test 323 of time-series data against models of drift, migration or selection. Heredity 118:21-30.

324

325 Johnson MS. 2011. Thirty-four years of climatic selection in the land snail Theba pisana.

326 Heredity 106: 741-748.

327

328

329

Kingsolver JG, Pfennig DW. 2007. Patterns and power of phenotypic selection in nature.

BioScience 57: 561-572.

330

331

Kinnison MT, Hairston NG, Hendry AP. 2015. Cryptic eco-evolutionary dynamics. Annals of the 332 New York Academy of Sciences 1360: 120-125.

333

334 Le Rouzic A, Hansen TF, Gosden TP, Svensson EI. 2015. Evolutionary time-series analysis 335 reveals the signature of frequency-dependent selection on a female mating polymorphism. The 336 American Naturalist 185:E182-E196. 
338 Linck E, Bridge ES, Duckles JM, Navarro-Sigüenza, Rohwer S. 2016. Assessing migration 339 patterns in Passerina ciris using the world's bird collections as an aggregated resource. PeerJ 340 4:e1871; DOI 10.7717/peerj.1871

341

342 Murray J.J. 1975: The genetics of the Mollusca. In: Handbook of genetics (ed. R.C. King), vol. 343 3, pp. 3-31. New York: Plenum.

344

345 Ożgo M. 2008. Current problems in the research of Cepaea polymorphism. Folia Malacologica 346 16: 55-60.

347

348

Ożgo M, Schilthuizen M. 2012. Evolutionary change in Cepaea nemoralis shell colour over 43 349 years. Global Change Biology 18:74-81. doi: 10.1111/j.1365-2486.2011.02514.x

350

351

Palkovacs EP, Kinnison MT, Correa C, Dalton CM, Hendry AP. 2012. Evolutionary

352 Applications 5:183-191.

353 Petrovan SO, Schmidt BR. 2016. Volunteer conservation action data reveals large-scale and 354 long-term negative population trends of a widespread amphibian, the common toad (Bufo bufo). 355 PLoS ONE 11:e0161943. doi:10.1371/

356 journal.pone.0161943

357

358 Schilthuizen, M., 2018. Darwin Comes to Town. How the Urban Jungle Drives Evolution. 359 Quercus Books, London, UK.

360

361

Schilthuizen M, Vairappan CS, Slade EM, Mann DJ, Miller JA. 2015. Specimens as primary 362 data: museums and “open science”. Trends in Ecology and Evolution 20:1-2.

363

364 Shackell NL, Frank KT, Fisher JAD, Petrie B, Leggett WC. 2010. Decline in top predator body 365 size and changing climate alter trophic structure in an oceanic ecosystem. Proceedings of the 366 Royal Society B: 277:1353-1360. 
368 Sharpe DM, Hendry AP. 2009. Life history change in commercially exploited fish stocks: an 369 analysis of trends across studies. Evolutionary Applications 2:260-275.

370

371 Siepielski AM, DiBattista JD, Carlson SM. 2009. It's about time: the temporal dynamics of 372 phenotypic selection in the wild. Ecology Letters 12:1261-1276.

373

374 Siepielski AM, Gotanda KM, Morrissey MB, Diamond SE, DiBattista JD, Carlson SM. 2013.

375 The spatial patterns of directional phenotypic selection. Ecology Letters 16:1382-1392.

376

377 Silvertown J, Cook L, Cameron R, Dodd M, McConway K, Worthington J, Skelton P, Anton C, 378 Bossdorf O, Baur B, Schilthuizen M, Fontaine B, Sattmann H, Bertorelle G, Correia M, Oliveira 379 C, Pokryszko B, Ożgo M, Stalažs A, Gill E, Rammul U, Sólymos P, Féher Z, Juan X. 2011. 380 Citizen science reveals unexpected continental-scale evolutionary change in a model organism. 381 PLoS ONE 6:e18927.

382

383 Turney S, Cameron ER, Cloutier CA, Buddle CM. 2015. Non-repeatable science: assessing the 384 frequency of voucher specimen deposition reveals that most arthropod research cannot be 385 verified. PeerJ 3:e1168; DOI 10.7717/peerj.1168

386

Van Heurn WC. 1943. Stabiliteit van populaties van Cepaea nemoralis (L.). Basteria 8:59-63. 388

389 390

Van Heurn WC. 1945. Stabiliteit van populaties van Cepaea nemoralis (L.), vervolg. Basteria $9: 39-43$.

391

392

Vinarski MV. 2016. Annotated type catalogue of lymnaeid snails (Mollusca, Gastropoda) in the 393 collection of the Natural History Museum, Berlin. Zoosystematics and Evolution 92:131-152.

394

395 Wolda H. 1969. Stability of a steep cline in morph frequencies of the snail Cepaea nemoralis 396 (L.). Journal of Animal Ecology 38:623-635.

397 
398 Yeates DK, Zwick A, Mikheyev AS. 2016. Museums are biobanks: unlocking the genetic 399 potential of the three billion specimens in the world's biological collections. Current Opinion in 400 Insect Science 18:83-88. 
402

403

404 Figure 1. Proportional variation in morph frequencies for all sites in all years. A-C, Shell

405 ground colour morphs. D-F, Banding categories - Mid: mid-banded (00300); Three:

406

407 three-banded (00345); Five: five-banded (12345); Other: other banding categories. G-I,

408 Proportion of Yellow effectively unbanded (YeU). Numbers indicate total count. *: $p<$ 409 
411 Supplementary Data 1. Allemansgeest, Empe, Lobith comparisons. Results of the chi-square 412 homogeneity tests. Shell colour: Y: yellow; P: pink; B: brown. Banding: M: mid-banded 413 (00300); T: three-banded (00345); F: five-banded (12345); O: other banding categories.

414

415 Supplementary Data 2. Full details of the original and the resampled collections from Lobith, 416 including a photo of the contemporary habitat.

417

418 Supplementary Data 3. Full details of the original and the resampled collections from Empe, 419 including a photo of the contemporary habitats.

420

421 Supplementary Data 4. Full details of the original and the resampled collections from

422 Allemansgeest, including a photo of the contemporary habitat.

423

424 


\section{Figure 1}

Proportional variation in morph frequencies for all sites in all years.

A-C, Shell ground colour morphs. D-F, Banding categories - Mid: mid-banded (00300); Three:

three-banded (00345); Five: five-banded (12345); Other: other banding categories. G-I,

Proportion of Yellow effectively unbanded (YeU). Numbers indicate total count. *: $p<0.05$;

$* *: p<0.01 ; * * *: p<0.001$. 

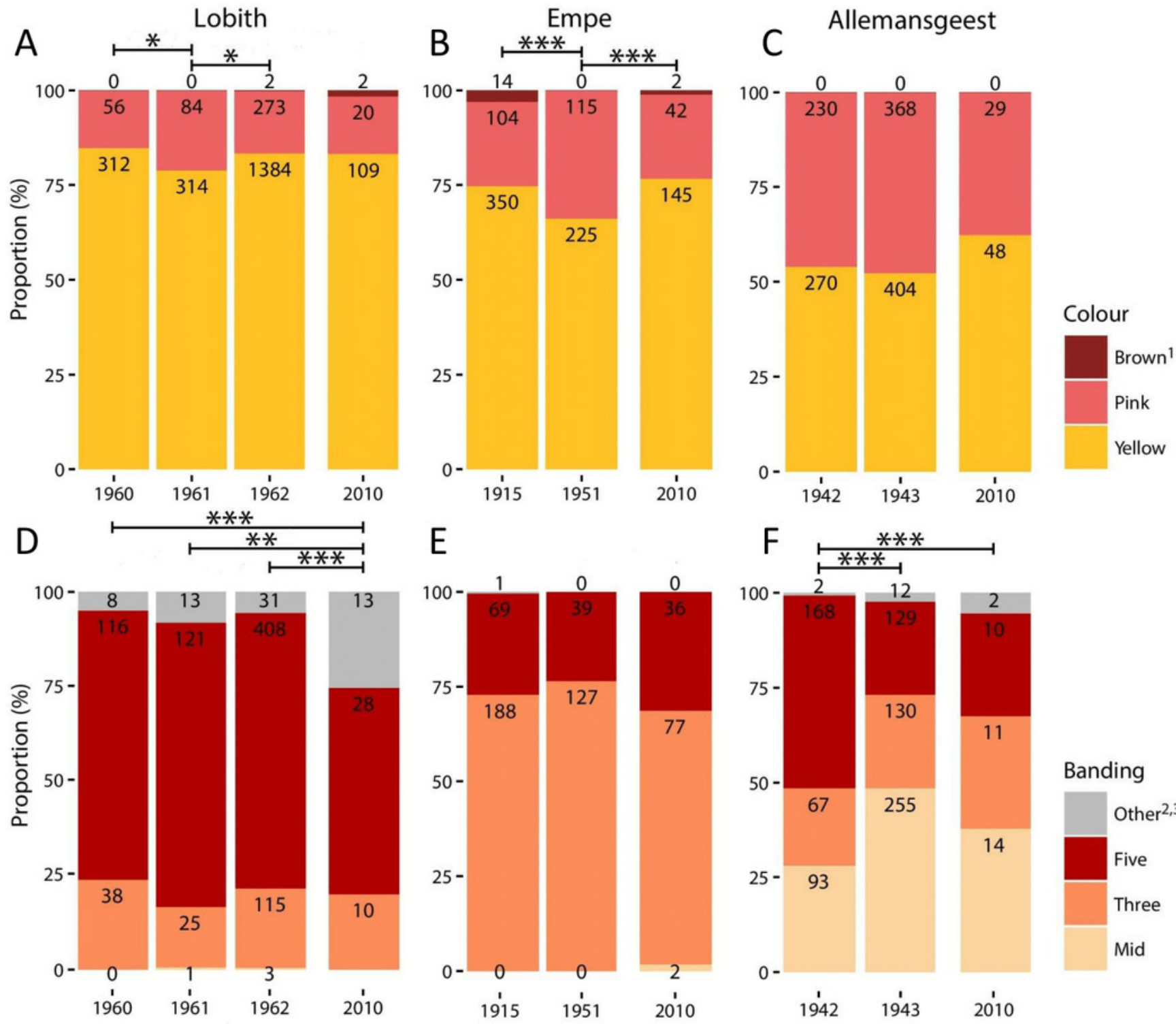

Banding
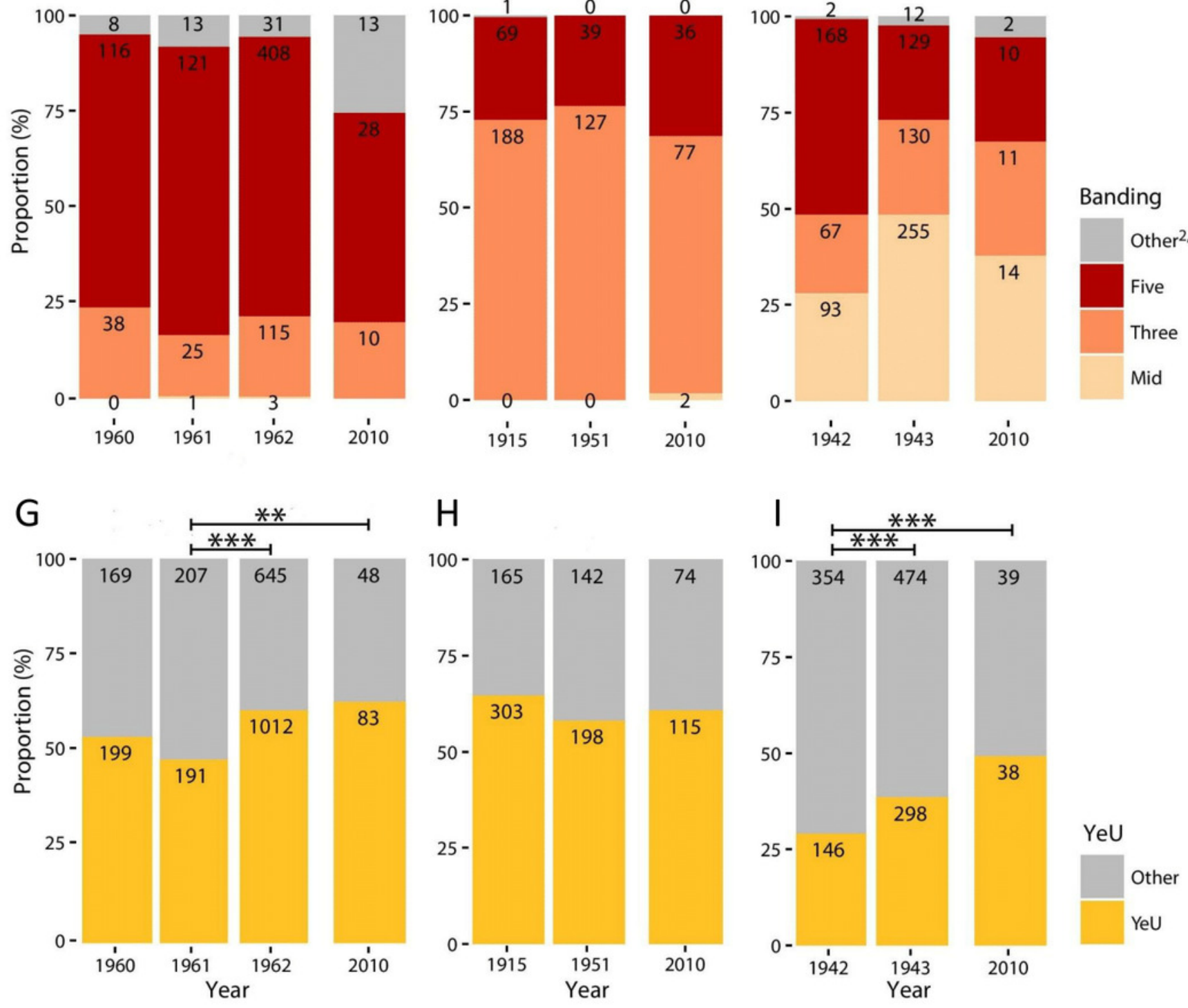